\title{
POLÍTICAS EDUCACIONAIS EM TEMPOS DE GOLPE: ENTREVISTA COM DERMEVAL SAVIANI
}

\author{
Jorge Fernando Hermida ${ }^{1}$ \\ JAILTON DE SOUZa LiRA ${ }^{2}$
}

\section{Introdução}

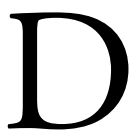

ermeval Saviani nasceu em 25 de dezembro de 1943 em Santo Antônio de Posse, no interior do Estado de São Paulo. É graduado em Filosofia (PUC/SP, 1966), doutor em Filosofia da Educação (PUC/SP, 1971), livre-docente em História da Educação (Unicamp, 1986) e realizou estágio sênior (pós-doutorado) na Università degli Studi di Padova (Itália, 1994-1995). Atualmente aposentado, Saviani é professor emérito da Universidade Estadual de Campinas (Unicamp), pesquisador emérito do CNPq e coordenador-geral do Grupo de Estudos e Pesquisas "História, Sociedade e Educação no Brasil" (HISTEDBR).

Suas primeiras experiências em magistério no ensino superior aconteceram quando ainda era estudante do curso de Filosofia na PUC/SP, no ano de 1966. A convite do professor Joel Martins, assumiu como monitor a cadeira de Filosofia da Educação para o curso de Pedagogia. Um ano mais tarde, tornou-se docente da instituição para ministrar Fundamentos Filosóficos da Educação e também começou a ministrar aulas de Filosofia em instituiçóes públicas e privadas no ensino médio. Após defender sua tese de doutorado, trabalhou na pós-graduação da PUC/SP de 1972 até 1988. De agosto de 1975 a março de 1978, atuou em período integral na Universidade Federal de São Carlos (UFSCar), na qual foi cofundador e coordenador do curso de Pós-Graduação em Educação. Em 1980, ingressou na Unicamp em período parcial e passou, em janeiro de 1989, ao regime de dedicação exclusiva, no qual continuou desenvolvendo suas atividades de ensino, pesquisa e pós-graduação até sua aposentadoria. Ele permanece até hoje como docente dessa instituição na condição de professor colaborador pleno do Programa de Pós-Graduação em Educação.

\footnotetext{
${ }^{1}$ Universidade Federal da Paraíba, Programa de Pós-Graduação em Educação e Mestrado Profissional em Gestão em Organizaçóes Aprendentes - João Pessoa (PB), Brasil.

E-mail: jorgefernandohermida@yahoo.com.br

${ }^{2}$ Universidade Federal de Alagoas, Centro de Educação - Maceió (AL), Brasil.

E-mail: jailtonsouzalira@gmail.com

DOI: 10.1590/ES0101-73302018190268
} 
O professor Saviani prestou relevantes serviços ao desenvolvimento do ensino, da ciência e da cultura, seja transmitindo os seus saberes (publicando livros, capítulos de livros e artigos de revistas), percorrendo as universidades brasileiras para ministrar cursos e palestras desde a década de 1980 ou formando e qualificando professores, mestres e doutores, tendo em vista que tantos fizeram cursos sob a sua orientação e, também, muitos outros tiveram o privilégio de assistir a suas aulas.

Como pesquisador, o professor Saviani tem dado importante contribuição para o entendimento do papel central que ocupa a educação em sociedades divididas em classes, bem como da transformação social que a prática educativa possibilita, agindo como elemento central no combate à exclusão social que assola e marginaliza setores significativos da nossa população. Destacam-se nas suas principais obras alguns livros que se tornaram clássicos da literatura educacional, dentre os quais ressaltamos: Escola e Democracia (1983); Pedagogia Histórico-Critica: primeiras aproximaçóes (1991); História das ideias pedagógicas no Brasil (2007); A pedagogia no Brasil: história e teoria (2008); Pedagogia Histórico- Critica e luta de classes na educação escolar (em coautoria com Newton Duarte, 2012); História do tempo e tempo da história (2015) e Pedagogia Histórico-Critica, educação e revolução: 100 anos da Revolução Russa (2017).

Fundamentando-se na perspectiva cultural histórico-proletária, nas bases da psicologia histórico-cultural, no materialismo histórico e dialético, e na filosofia da práxis, o professor Saviani elaborou a pedagogia histórico-crítica (SAVIANI, 2013). Convidando os educadores para colocarem-se na perspectiva da classe trabalhadora, o autor apresenta uma proposta educacional que procura "romper" com a velha concepção de cultura dominante (a perspectiva enciclopédico-burguesa), de modo que o saber escolar, historicamente dominado e controlado pela burguesia, também possa ser apropriado pela classe trabalhadora. A classe trabalhadora, ao se apropriar do saber "burguês", irá direcioná-lo para o sentido inverso, desarticulando-o dos interesses burgueses e colocando-o a serviço da sua classe (perspectiva cultural histórico-proletária).

A comunidade acadêmica e científica tem valorizado as contribuiçóes de Saviani para a educação brasileira, tendo ele recebido, até o momento, os seguintes prêmios e homenagens: Medalha do Mérito Educacional do Ministério da Educação (1994); Prêmio Zeferino Vaz de produção científica (1997); Professor Emérito da Unicamp (2002); Pesquisador Emérito do CNPq (2010); Prêmio Jabuti de 2008 (primeiro lugar na categoria Educação, Psicologia e Psicanálise), com História das Ideias Pedagógicas no Brasil; Prêmio Jabuti de 2014 (segundo lugar na categoria Educação), com Aberturas para a História da Educação e o Prêmio Jabuti de 2016 (segundo lugar na categoria Educação), com História do tempo e tempo da história. Em 2016, foi agraciado com o Prêmio Anísio Teixeira, na categoria Educação Básica. Como a cerimônia da entrega da oitava edição do prêmio 
havia sido marcada para 26 de outubro de 2016, nas dependências do Ministério da Educação (MEC) - época na qual já havia sido consumado o impeachment e o golpe jurídico-midiático-parlamentar que colocou Michel Temer na Presidência da República —, Saviani não compareceu para receber a premiação, por ser fiel aos princípios democráticos que apregoa.

Em 16 de maio de 2017, a Universidade Tiradentes (UNIT) entregou ao professor Saviani o Título de Doutor Honoris Causa. Idêntica homenagem recebeu em 7 de novembro do mesmo ano, na Universidade Federal da Paraíba (UFPB), pela valiosa contribuição política e acadêmica de sua obra para a melhoria da educação.

A presente entrevista tem como tema "Políticas Educacionais em tempos de golpe", na qual discutimos com o professor Saviani a respeito do atual momento político, caracterizado pelo autor como sendo de ruptura com a institucionalidade democrática, com foco, em particular, nos desdobramentos que o golpe trouxe para a educação brasileira.

Os autores desta entrevista têm certeza de que esta servirá para conhecer e divulgar o posicionamento político e pedagógico do professor Saviani a respeito do difícil momento que vive nosso país desde 2016.

\section{Entrevista}

Entrevistadores: Professor Saviani, nesta entrevista procuramos entender as recentes mudanças que estão acontecendo na educação, relacionando-as com fatos sociais e políticos determinantes. Tendo em vista os acontecimentos políticos que vêm ocorrendo a partir do ano de 2016 (desde o impeachment da presidenta Dilma Rousseff), como o senhor caracterizaria o atual momento político no Brasil?

Dermeval Saviani: A meu ver, o atual momento político no Brasil se explica a partir de um duplo componente.

O primeiro é de caráter global e tem a ver com a fase atual do capitalismo, que entrou em profunda crise de caráter estrutural, situação em que a classe dominante, não podendo se impor racionalmente, precisa recorrer a mecanismos de coerção, combinados com iniciativas de persuasão que envolvem o uso maciço dos meios de comunicação e a investida no campo da educação escolar, tratada como mercadoria e transformada em instrumento de doutrinação.

O segundo componente tem a ver com a especificidade da formação social brasileira, marcada pela persistência de sua classe dominante, sempre resistente em incorporar a população, temendo a participação das massas nas decisōes políticas. É essa classe dominante que, agora, no contexto da crise estrutural do capitalismo, dá vazão ao seu ódio de classe, mobilizando uma direita 
raivosa que se manifesta nos meios de comunicação convencionais, nas redes sociais e nas ruas.

Nesse contexto, a aprovação do impedimento da presidenta reeleita, sem que ficasse caracterizado o crime de responsabilidade, único motivo previsto na Constituição para justificar o impeachment, caracterizou-se como um golpe jurídico-midiático-parlamentar. Em consequência, rompeu-se a institucionalidade democrática, abrindo margem para todo o tipo de arbítrio. Assim, estamos vivendo um verdadeiro suicídio democrático, ou seja, as próprias instituiçóes ditas democráticas golpeiam o Estado Democrático de Direito pela ação articulada da grande mídia, do Parlamento e do Judiciário, que, pelo golpe, se apossaram do Executivo.

Entrevistadores: $\mathrm{Na}$ opiniāo do cientista político Armando Boito Júnior, um momento marcante na história política recente do nosso país foi quando o governo Dilma Rousseff iniciou uma ofensiva política neodesenvolvimentista, que procurou promover o crescimento econômico (redução da taxa Selic, desvalorizaçáo do real, isençóes fiscais para o capital produtivo etc.), sem ter eliminado antes os pilares do modelo capitalista neoliberal e do grande capital internacional. A tentativa de defender o segmento produtivo da açáo da grande burguesia interna, em detrimento dos interesses bancários dessa classe economicamente dominante e do capital internacional, acirrou um conflito que sempre esteve presente. Segundo ele, foram justamente essas forças políticas e econômicas que iniciaram uma ofensiva contra o governo no início do ano de 2013. Essa análise histórica procede? Qual é o seu ponto de vista?

Dermeval Saviani: Manifesto minha concordância, em termos gerais, com essa análise do Prof. Armando Boito Júnior. De fato, se na década de 1960, no contexto da guerra fria, ocorreram golpes de força que recorreram às Forças Armadas, com o apoio da CIA, agora a estratégia mudou na direção da desestabilização seguida de destituição, por via parlamentar, de governos populares. Essa iniciativa vem sendo posta em prática em diferentes países, especialmente naqueles em que os Estados Unidos têm interesses econômicos ou politicamente estratégicos. Daí as mobilizaçóes ocorridas em países como Tunísia, Egito, Líbia (a chamada “primavera árabe”), Rússia e Ucrânia e numa longa guerra civil na Síria. Na América do Sul, após o Paraguai, os alvos imediatos são o Brasil e a Venezuela, não por acaso, dotados de grandes reservas de petróleo, esboçando-se movimento semelhante na Bolívia e no Equador, sendo que, na Argentina, a vitória da direita nas eleições tornou desnecessário o recurso ao golpe jurídico-parlamentar.

É nesse contexto que ocorreu no Brasil, em 31 de agosto de 2016, o golpe mediante o qual o Senado Federal destituiu Dilma Rousseff da presidência da República. Ao desrespeitar a Constituiçáo, depondo uma presidenta que náo 
cometeu crime algum, quebrou-se a institucionalidade democrática. Sem crime, a presidenta, na vigência do regime democrático, só poderia ser julgada pelo próprio povo no exercício de sua soberania.

O julgamento no Senado Federal teve todos os ingredientes de uma farsa. Os acusadores, em nenhum momento, chegaram a apresentar qualquer prova. Ao contrário, vários senadores afirmaram que não se tratava de crime de responsabilidade, mas que iriam votar a favor do impeachment alegando que a crise econômica teria sido provocada pelo governo da presidenta e afirmando que o impedimento era "exigido pelas ruas". Ora, como registrou a repórter Luiza Villaméa numa reportagem da Revista Brasileiros (n. 109, agosto de 2016, p. 26-38), as manifestações pró-impeachment foram organizadas por entidades financiadas com recursos americanos, o que é eloquentemente ilustrado com o caso de Kim Patroca Kataguiri. Ele acabou por largar o curso de Economia na Universidade Federal do ABC "para se dedicar integralmente ao Movimento Brasil Livre (MBL)" (VILLAMÉA, 2016, p. 29). E o que é o MBL? "É um movimento derivado do Estudantes pela Liberdade (EPL), a filial brasileira da americana Students for Liberty, financiado pela Atlas Network" (VILLAMÉA, 2016, p. 29). Enfim, todos os institutos e movimentos que vêm se mobilizando tendo em vista golpear a democracia no Brasil recebem recursos de fontes como o "Cato Institute e o Charles Koch Foudation, vinculadas à família Koch, uma das mais ricas do mundo, com vastos interesses no setor petrolífero" (VILLAMÉA, 2016, p. 29). E vêm os senadores golpistas afirmar que estariam, com o impeachment, atendendo à voz das ruas! Aqui vale a ironia: só se estão se referindo à voz da Wall Street, a rua de Nova York, símbolo do sistema financeiro mundial. De fato, o governo que assumiu o poder em consequência do golpe vem se pondo explicitamente a serviço dos interesses financeiros dos bancos e do capital internacional.

Entrevistadores: $\mathrm{O}$ crescimento das forças conservadoras e de extrema-direita são fatos facilmente verificáveis nos últimos anos. Em sua opinião, como foi possível um país de recente tradição democrática (do ponto de vista histórico) dar esta guinada ideológica táo radical apesar do maior grau de conscientizaçáo das camadas populares e da ampla participação dos movimentos sociais em torno das suas demandas específicas? Que papel coube (ou não) à educação neste processo?

Dermeval Saviani: Como assinalei na resposta à primeira pergunta, a sociedade capitalista, na sua forma atual, entrou numa profunda crise. Nessas condiçóes, a classe dominante já não pode justificar-se racionalmente, abrindo-se espaço para sectarismos. Sendo estrutural, a crise afeta todo o sistema social. Por isso estamos assistindo a um recrudescimento das forças de direita em todo o globo.

No Brasil, o regime democrático esteve sempre em risco porque, considerando a tendência da população de escolher, especialmente para os cargos majoritá- 
rios, os menos piores de seu ponto de vista, que são os piores do ponto de vista dominante, os governantes de tendência popular sempre foram alvos de tentativas de golpe. Daí o caráter espúrio de nossa democracia, alternando a forma restrita, quando o jogo democrático é formalmente assegurado, com a forma excludente, em que a denominação "democracia” aparece como eufemismo de ditadura. Atualmente, são as próprias instituiçôes democráticas que estão sendo corrompidas por uma espécie de "Estado de exceção". Entendo, pois, que essa "guinada ideológica radical" constitui uma reação intempestiva exatamente contra a relativa conscientização das camadas populares e a participação dos movimentos sociais atuando em função de suas demandas específicas. A esse avanço das forças populares no processo de redemocratização do país após a ditadura militar correspondeu a reação das forças conservadoras difundindo versóes ideológicas orquestradas pela mídia ancorada nas camadas médias, que tenderam a ver nos programas sociais dos governos do PT um favorecimento dos setores populares em detrimento de seu sentimento de superioridade diante das massas. Criou-se, assim, um caldo de cultura favorável a um conservadorismo que, em suas versões mais radicais, se aproxima de atitudes nazifascistas. E a educação pouco pôde fazer para se contrapor a esse caldo cultural, à vista de sua precarização e das pressóes constantes para se ajustar, ela própria, aos mecanismos de mercado que estão na base dessa onda reacionária.

Entrevistadores: Por falar em ideologias, o Movimento Escola Sem Partido, apesar de ter sua lei declarada inconstitucional pelo Supremo Tribunal Federal, conseguiu significativo espaço de difusão e defesa das suas ideias nas camadas mais amplas da sociedade, incluindo importantes segmentos da mídia. Como entender isso? Como equilibrar a esta "batalha das ideias"?

Dermeval Saviani: O “Escola sem Partido" é um componente da onda reacionária à qual me referi na resposta anterior, tendo encontrado um espaço favorável de difusão no mencionado caldo de cultura. Para equilibrar essa "batalha de ideias", contamos com uma teoria pedagógica cujo entendimento das relaçóes entre educação e política é diametralmente oposto àquele esposado pela autodenominada "Escola sem Partido". Trata-se da pedagogia histórico-crítica (SAVIANI, 2013).

Para a pedagogia histórico-crítica, na sociedade de classes, portanto, na nossa sociedade, a educação é sempre um ato político, dada a subordinação real da educação à política (SAVIANI, 2012, p. 81-90). Dessa forma, agir como se a educação fosse isenta de influência política é uma forma eficiente de colocá-la a serviço dos interesses dominantes. E é esse o sentido do programa "Escola sem Partido", que visa, explicitamente, subtrair a escola do que seus adeptos entendem como "ideologias de esquerda", colocando-a sob a influência da ideologia e dos partidos da direita, portanto, a serviço dos interesses dominantes. Ao proclamar a neutralidade da educação em relação à política, o objetivo a atingir é o de estimular o idealismo dos professores, fazendo-os acreditar na autonomia da educação 
em relação à política, o que os fará atingir o resultado inverso ao que estão buscando: em lugar de, como acreditam, estar preparando seus alunos para atuar de forma autônoma e crítica na sociedade, estaráo formando para ajustá-los melhor à ordem existente e aceitar as condiçóes de dominação às quais estão submetidos. Eis por que a proposta da escola sem partido se origina de partidos situados à direita do espectro político. A denominação "Escola sem Partido" camufla, pois, o fato de que se trata da escola dos partidos da direita, os partidos conservadores e reacionários que visam manter a situação vigente com todas as injustiças e desigualdades que caracterizam a forma de sociedade dominante no mundo de hoje.

Entrevistadores: De que forma o senhor avalia, ainda nesta questão do projeto "Escola sem Partido", a articulação dos movimentos fascistas com a ação das igrejas cristâs? Qual deveria ser a estratégia para desconstruir as iniciativas do "Escola sem Partido"?

Dermeval Saviani: A articulação dos movimentos fascistas, correspondente à onda conservadora com o caldo cultural reacionário referido na resposta à terceira questão, foi reforçada pelo fundamentalismo religioso assumido por diferentes seitas surgidas nos últimos 40 anos, dedicadas a explorar a boa-fé das camadas mais desvalidas da sociedade. Tal situação contém certa analogia com a análise de Marx (2011) em O dezoito Brumário de Luis Bonaparte, quando mostra que o lumpemproletariado serviu de massa de manobra ao golpe de Luís Bonaparte, desferido em 2 de dezembro de 1851. Para desconstruir as iniciativas do "Escola sem Partido", proponho a retomada da estratégia da resistência ativa, que implica dois requisitos:

- que seja coletiva, pois as resistências individuais não têm força para se contrapor ao poder dominante exercido pelo governo ilegítimo e antipopular;

- que seja propositiva, isto é, capaz de apresentar alternativas às medidas do governo e de seus asseclas.

Podemos ver que esses dois requisitos correspondem ao duplo papel da educação: de resistência e de transformação.

Entrevistadores: Em 2014, foi sancionado o Plano Nacional de Educação. A meta 20 previu que o Brasil deveria investir $10 \%$ do PIB ao longo da sua vigência. Com o cenário macroeconômico recessivo e a nova orientaçáo ideológica do governo federal após o golpe do impeachment, que alternativas o senhor acredita que poderiam ser encontradas para o financiamento adequado da educação brasileira, dado que esta meta sequer entrou no orçamento da Uniáo em 2018, sendo pouco provável que vá ser contemplada nos próximos anos? Quer dizer que o plano se tornou inviável em termos pragmáticos? 
Dermeval Saviani: O Plano Nacional de Educação, aprovado em 2014 com vigência até 2024 , está, todo ele, inviabilizado, uma vez que, para se atingir as metas, sáo necessários recursos financeiros, o que resultou impedido pela aprovação da Emenda Constitucional que proíbe, por 20 anos, a ampliação dos gastos públicos para além do índice de inflação do ano anterior (BRASIL, 2014). Assim é que várias de suas metas já venceram sem serem atingidas e as que ainda não venceram não têm mais a mínima chance de se viabilizar. Vejamos:

- $\quad$ metas já vencidas: Meta 1 - universalizar, até 2016, a educação infantil na pré-escola para as crianças de 4 a 5 anos de idade; Meta 3 - universalizar, até 2016, o atendimento escolar para toda a população de 15 a 17 anos de idade; Meta 18 - assegurar, no prazo de 2 anos (portanto, até 2016), a existência de planos de carreira para os profissionais de todos os sistemas de ensino; Meta 19 - assegurar condiçóes, no prazo de 2 anos (portanto, também até 2016), para a efetivação da gestão democrática;

- $\quad$ metas a vencer: Meta 2 - universalizar o ensino fundamental de 9 anos até o último ano de vigência deste PNE (2024); Meta 4 - universalizar, para a população de 4 a 17 anos, a educação especial até 2024; Meta 20 - atingir, no mínimo, o patamar de 7\% do PIB, no quinto ano de vigência (2019) e, no mínimo, o equivalente a 10\% do PIB ao final do decênio (2024).

Mas, com a Emenda Constitucional apelidada de "PEC do fim do mundo", todas essas metas já estáo inviabilizadas pelo menos até 2037.

Entrevistadores: Existem gargalos evidentes na educação, em termos especialmente de acesso e permanência. No caso da educação infantil, o maior problema é o déficit de vagas ofertadas pelo setor público. Como equacionar esta questáo, visto que os munícipios dependem da colaboração federativa, que praticamente se resume à colaboração conjuntural do governo federal por meio de programas específicos?

Dermeval Saviani: O equacionamento da educação infantil, assim como dos demais "gargalos evidentes" da educação brasileira, consiste na instituição de um amplo e consistente Sistema Nacional de Educação, pelo qual todos os níveis e modalidades de educação estariam articulados e todas as açôes correspondentes seriam realizadas em regime de colaboração pelas três instâncias federativas: a União, os Estados/Distrito Federal e os Municípios. Impóe-se, assim, quebrar a lógica hierarquizada que situa cada nível de ensino sob a responsabilidade de cada instância federativa em sentido ascendente: os municípios com a educação infantil e o ensino fundamental; os estados com o ensino fundamental (juntamente com o município) e o ensino médio; e a União com as escolas técnicas e 
o ensino superior. Em lugar dessa responsabilização verticalizada, cabe fazer uma distribuição horizontalizada, na qual cada ente federativo concorrerá na medida de suas peculiaridades e de suas competências específicas consolidadas pela tradição. Nesse rearranjo, a responsabilidade principal dos municípios incidirá sobre a construçáo e conservação dos prédios escolares e de seus equipamentos, assim como sobre a inspeção de suas condições de funcionamento, além, é claro, dos serviços de apoio, como merenda e transporte escolar etc. Efetivamente, são esses os aspectos em que os municípios têm experiência consolidada. Tratei desse assunto no Capítulo IV — "Indicações para a construção do Sistema Nacional de Educação no Brasil", do livro Sistema Nacional de Educação e Plano Nacional de Educação: significado, controvérsias e perspectivas, p. 43-61, 2a ed. revista e ampliada, publicado em 2017 (SAVIANI, 2017b).

Entrevistadores: A reforma do ensino médio foi um dos temas mais tratados pela comunidade educacional nos últimos tempos. Aprovada pelo Ministério da Educação em função da correlação de forças no Congresso Nacional, sua execução será completamente inviabilizada por conta das desigualdades regionais no tocante a este nível de ensino. Mesmo havendo consenso entre os educadores sobre a necessidade de se fazer alteraçôes no modelo existente, não parece existir propostas afinadas com tal entendimento. O que o senhor pensa sobre a reforma aprovada e em que medida poderiam ser apresentadas propostas mais condizentes com as finalidades de uma educação de caráter emancipatório?

Dermeval Saviani: A proposta aprovada corresponde ao intento do atual governo de ajustar a educação aos desígnios do capitalismo financeiro, buscando formar uma máo de obra dócil e a baixo custo. Para tanto, na contramão da tendência atual de empreender a unificação do ensino médio, fragmenta-o em cinco itinerários, argumentando com o princípio da flexibilidade que permitiria aos alunos a livre opção pelo itinerário que correspondesse aos respectivos projetos de vida, o que, na verdade, camufla a intenção de induzir a grande maioria à opção pelo quinto itinerário, ou seja, formação técnica e profissional. Com efeito, como atribuir a adolescentes na faixa dos 15 anos de idade a opção livre e consciente por um itinerário formativo segundo seu próprio projeto de vida? De fato, essa reforma retrocede à década de 1940, com as Reformas Capanema, quando o ensino médio foi dividido entre o ensino secundário, "destinado às elites condutoras" na reforma atual, correspondente aos quatro primeiros itinerários -, e o ensino técnico-profissional, subdividido nos ramos industrial, comercial e agrícola, destinado ao povo conduzido.

Uma proposta condizente com uma educação de caráter emancipatório implica a organização do ensino médio de forma unificada, não diretamente interessado profissionalmente. Partindo do conceito e do fato do trabalho como princípio educativo, delineei essa proposta observando que, se no ensino funda- 
mental a relação entre educação e trabalho é implícita e indireta, no ensino médio essa relação deverá ser trada de maneira explícita e direta. Portanto, no ensino médio já não basta dominar os elementos básicos do conhecimento, que resultam e, ao mesmo tempo, contribuem para o processo de trabalho na sociedade, como é o caso do ensino fundamental. Ao ensino médio cabe explicitar como a ciência, a potência espiritual, se converte em potência material no processo de produção. E tal explicitação deve envolver o domínio não apenas teórico, mas também prático. O horizonte que deve nortear a organização do ensino médio é o de propiciar aos alunos o domínio dos fundamentos científicos das múltiplas técnicas produtivas e não o mero adestramento técnico. Tal concepção implica a generalizaçáo do ensino médio como formação necessária para todos, independentemente do tipo de ocupação que cada um venha a exercer na sociedade.

Entrevistadores: Os defensores da educação pública utilizam frequentemente a expressão "educação não é mercadoria". Contudo, os setores privatistas têm obtido vitórias significativas, nesse sentido, no ensino superior, como a implantação do PROUNI, do FIES e a formalização das parcerias público-privadas, que, na prática, transferem recursos públicos para a iniciativa privada, além da aprovação indiscriminada dos cursos superiores presenciais e à distância. Ou seja, o Estado vem atuando no sentido de favorecer o privado em detrimento do público. Em uma sociedade de mercado, como impedir que a educação se transforme, de fato, em mercadoria, como estamos observando ultimamente?

Dermeval Saviani: De fato, como assinala Marx na abertura d'O Capital, "a riqueza das sociedades onde rege a produção capitalista configura-se em 'imensa acumulação de mercadorias', e a mercadoria, isoladamente considerada, é a forma elementar dessa riqueza" (MARX, 1968, p. 41). Assim sendo, a tendência do capitalismo é converter tudo em mercadoria, como já fora antes formulado no Manifesto do Partido Comunista (MARX; ENGELS, 1968, p. 25): a burguesia "afogou os fervores sagrados do êxtase religioso [...] nas águas geladas do cálculo egoísta” e "fez da dignidade pessoal um simples valor de troca". Mas, se trata de um processo contraditório. Por isso, no final do primeiro volume d'O Capital, Marx (MARX, 1968, p. 575) afirma que, com o capitalismo, são destruídas todas as formas antigas e transitórias, substituindo-as pelo "domínio direto e franco do capital. Com isso, generaliza também a luta direta contra esse domínio". Favorecendo as condições materiais do processo de produção, "aguça as contradiçóes e os antagonismos da forma capitalista de produção amadurecendo, ao mesmo tempo, os elementos formadores de uma sociedade nova" (Idem, ibidem.). Portanto, se nessa fase de crise estrutural do capitalismo a pressão para transformar a educação em mercadoria, de modo especial a de nível superior, assume formas agudas, também a resistência a essa pressão deve ser fortalecida, pois, ainda citando Marx (Idem, p. 559), "o desenvolvimento das contradiçôes de uma forma histórica de produção é o único caminho de sua dissolução e do estabelecimento de uma nova forma”. 
Entrevistadores: Suas pesquisas recentes buscam identificar os principais caminhos da história da educação brasileira e formulam uma periodização que cobre toda a história de nossa educaçáo, desde as origens até os dias atuais. Poderia apresentar-nos sua proposta de periodização, valorizando a descrição do momento atual?

Dermeval Saviani: A periodização por mim proposta para a história da educação brasileira está expressa no livro História das ideias pedagógicas no Brasil (4a ed., 2013, p. 19-29):

- $\quad 1^{\circ}$ Período (1549-1759): Monopólio da vertente religiosa da pedagogia tradicional, subdividido nas seguintes fases:

1. Uma pedagogia brasílica ou o período heroico (1549-1599);

2. A institucionalização da pedagogia jesuítica ou o Ratio Studiorum (1599-1759).

- $\quad$ 2o Período (1759-1932): Coexistência entre as vertentes religiosa e leiga da pedagogia tradicional, subdividido nas seguintes fases:

1. A pedagogia pombalina ou as ideias pedagógicas do despotismo esclarecido (1759-1827);

2. Desenvolvimento da pedagogia laica: ecletismo, liberalismo e positivismo (1827-1932).

- $\quad 30$ Período (1932-1969): Predominância da pedagogia nova, subdividido nas seguintes fases:

1. Equilíbrio entre a pedagogia tradicional e a pedagogia nova (1932-1947);

2. Predomínio da influência da pedagogia nova (1947-1961);

3. Crise da pedagogia nova e articulação da pedagogia tecnicista (1961-1969).

- 4o Período (1969-2001): Confronto entre a concepção produtivista de educação e as pedagogias críticas, subdividido nas seguintes fases:

1. Predomínio da pedagogia tecnicista, manifestações da concepção analítica de filosofia da educação e concomitante desenvolvimento da visão crítico-reprodutivista (1969-1980);

2. Ensaios contra-hegemônicos: pedagogias da "educação popular", pedagogias da prática, pedagogia crítico-social dos conteúdos e pedagogia histórico-crítica (1980-1991);

3. O neoprodutivismo e suas variantes: neoescolanovismo, neoconstrutivismo e neotecnicismo (1991-2001). 
Observe-se que os marcos dessa proposta de periodizaçáo são internos ao processo educativo, numa tentativa de superar as periodizaçóes baseadas em marcos externos dominantemente de caráter político ou econômico. Assim, em 1549, chegada dos primeiros jesuítas com um mandado real para catequizar os índios; 1599, promulgação do Ratio Studiorum, o método pedagógico dos jesuítas; 1759, expulsão dos jesuítas do império português e início das reformas pombalinas da instrução pública; 1827, promulgação da lei das escolas de primeiras letras; 1932, lançamento do Manifesto dos Pioneiros da Educação Nova; 1947, criação da comissão encarregada de elaborar o projeto da primeira Lei de Diretrizes e Bases (LDB); 1961, promulgada a primeira LDB; em 1969 entrou em vigor a lei da reforma universitária do período militar; 1980, realização da Primeira Conferência Brasileira de Educação (I CBE); 1991, VI e última CBE e, em 2001, entrou em vigor o primeiro Plano Nacional de Educação (PNE), decorrente da segunda Lei de Diretrizes e Bases da Educaçáo Nacional (LDB), promulgada em 20 de dezembro de 1996.

Mas a pergunta, além de pedir que apresente minha proposta de periodização, pede que eu estenda a periodização até o momento atual. Considerando que a periodização que propus tem como limite final o ano de 2001, é preciso partir desse ponto para chegar ao momento atual. De fato, não é fácil periodizar o momento presente, já que suas características básicas, estando ainda em movimento, não se encontram tipificadas do ponto de vista historiográfico. No entanto, em linhas gerais, entendo que não cabe considerar que teria emergido um novo período. Ou seja, estamos, ainda, no quarto período, iniciado em 1969, caracterizado pelo predomínio da concepçáo produtivista, que se acentuou nos últimos 15 anos. Penso que poderíamos acrescentar a esse quarto período uma quarta fase, iniciando-se em 2001, com a vigência do PNE, e estendendo-se até a entrada em vigor do novo PNE, em 2014. A característica mais saliente dessa fase é a avaliação de resultados aferida por meio de testes nacionais, o que já foi preparado na fase anterior, com a aprovação da LDB em 1996, e a reorganização do INEP, em 1997.

Efetivamente, a LDB, na versão do Substitutivo Darcy Ribeiro, que resultou de manobra regimental no Senado, instituiu um Sistema Nacional de Avaliação sob responsabilidade da União, com a função de assegurar um processo nacional de avaliaçấo do rendimento escolar nos ensinos fundamental, médio e superior e de avaliação das instituiçôes de ensino superior em todo o país. E, em 14 de fevereiro de 1997, foi editada a Medida Provisória no ${ }^{\circ} 1.568$ (BRASIL, 1997b), que, com a aprovação do Congresso Nacional, converteu-se na Lei no. 9.448, de 14 de março de 1997 (BRASIL, 1997a). Pelo enunciado das atribuições então definidas, vê-se que o INEP deixou de ser um órgão de realização e fomento à pesquisa educacional, de organização da documentação sobre educação e de disseminação das informaçóes educacionais, funçôes que lhe foram atribuídas desde sua fundação até a promulgação dessa lei, para se converter num órgão de avaliação da educação brasileira em todos os seus níveis e modalidades e de produção de estatísticas educacionais. 
Foi, de fato, uma verdadeira refundação, como definiu Maria Helena Castro, que na ocasião havia sido reempossada como presidente do INEP.

Poderíamos, pois, reformular o enunciado do quarto período nos seguintes termos:

- $\quad 4$ o Período (1969-2015): Predomínio da concepção produtivista de educação, subdividido nas três fases antes mencionadas e que ficam mantidas, acrescentando-se uma quarta fase assim enunciada:

4. Advento do modelo de avaliação orientado pela formação de rankings e baseado em provas padronizadas aplicadas uniformemente aos alunos de todo o país (2001-2015).

Esse modelo de avaliação iniciado no governo FHC teve continuidade no governo Lula e se incorporou ao PNE 2014-2024, cuja meta 7, que especifica as médias nacionais a serem atingidas para o IDEB e que visa melhorar o desempenho dos alunos no PISA é, de longe, a mais detalhada, sendo contemplada com 36 estratégias.

Cabe observar que o referido modelo não está centrado em pesquisa sobre a situação educacional brasileira. Ao contrário, sua inspiração vem dos instrumentos internacionais focados na mensuração de resultados. Sobre isso, é importante considerar a autocrítica efetuada por Diane Ravitch no livro The death and life of the great American School System: how testing and choice are undermining education, publicado em 2010 e traduzido no Brasil em 2011 pela Editora Sulina com o título Vida e Morte do Grande Sistema Escolar Americano: Como os Testes Padronizados e o Modelo de Mercado Ameaçam a Educação (RAVITCH, 2011).

Diane Ravitch foi secretária adjunta de Educação entre 1991 e 1993, no governo George $\mathrm{H}$. W. Bush, sendo, em seguida, indicada pelo então presidente Bill Clinton para assumir o National Assessment Governing Board, instituto responsável pelos testes federais. Firmou-se, assim, como uma das principais defensoras da reforma do ensino nos Estados Unidos, reforma essa que, baseada em metas, introduziu testes padronizados, responsabilização do professor e práticas corporativas de medição e mérito. No entanto, após 20 anos defendendo esse modelo que inspirou as medidas adotadas no Brasil, Ravitch (RAVITCH, 2010, p. 16) concluiu que "em vez de melhorar a educação, o sistema em vigor nos Estados Unidos está formando apenas alunos treinados para fazer uma avaliação".

No Brasil, esse modelo de avaliação orientado pela formação de rankings e baseado em provas padronizadas aplicadas uniformemente aos alunos de todo o país por meio da Provinha Brasil, Prova Brasil, ENEM ou ENADE está, na prática, convertendo todo o "sistema de ensino" numa espécie de grande "cursinho pré-vestibular", pois todos os níveis e modalidades de ensino estão se organizando em função da busca de êxito nas provas visando aumentar a pontuação no IDEB e no PISA. Caminham, portanto, na contramão das teorizações pedagógicas for- 
muladas nos últimos cem anos, para as quais a avaliação pedagogicamente significativa não deve se basear em exames finais e muito menos em testes padronizados. Devem, sim, procurar avaliar o processo, considerando as peculiaridades das escolas, dos alunos e dos professores.

Fica em aberto, enfim, se o momento atual, que se inicia com a apresentação do primeiro projeto "Escola sem Partido" na Câmara dos Deputados, em 23 de março de 2015, e com a reforma do ensino médio instituída pela Medida Provisória no 746 (BRASIL, 2016), de 22 de setembro de 2016, cuja marca são mudanças regressivas, deve dar início a um novo período ou se será definido como a quinta fase do $4^{\circ}$ Período. Penso que, se as forças que deram o golpe permanecerem por um tempo relativamente longo no poder, estaríamos iniciando um novo período, de caráter obscurantista, na educação brasileira. Caso consigamos reverter esse quadro no curto prazo, estaríamos diante de uma quinta fase desse período de predomínio do produtivismo, que, sendo superada, entraríamos num novo período de retomada do fortalecimento da educação pública como um elemento importante na luta pela superação do capitalismo e construção do socialismo.

Entrevistadores: Importantes segmentos da esquerda brasileira têm apostado todas as suas fichas da disputa eleitoral de 2018 para lograr a alteração deste quadro de retrocessos a que estamos fazendo alusão nesta entrevista. Considerando a imensa capacidade de unificação da classe dominante demonstrada atualmente, gostaríamos, para a conclusão desta entrevista, que o senhor considerasse os seguintes cenários:

- $\quad$ caso a esquerda democrática consiga a vitória eleitoral, como reverter tantos retrocessos históricos levando em conta a composição reacionária do Congresso Nacional e da unidade da classe dominante em torno das reformas antissociais?

- $\quad$ em caso de derrota (panorama mais provável), de que modo promover essa rearticulação dos segmentos sociais frente ao aprofundamento da política neoliberal e direitista em curso? Em suma, quais os horizontes são mais realistas e quais as estratégias de enfretamento?

Dermeval Saviani: Respondendo à questão colocada, permita-me considerar, para 2018, os seguintes cenários:

- Lula disputa as eleiçóes, vence e é empossado. Nesse caso, vejo duas possibilidades: ele negocia com os conservadores ao centro e à direita para assegurar a governabilidade. Nesse caso, não revogará substantivamente as medidas antinacionais e antipopulares tomadas pelo governo golpista. Voltaremos, então, ao status quo anterior ao golpe, numa situação, porém, mais desfavorável às camadas populares. A segunda possibilidade é Lula ter chegado à conclusão de que é um tiro no pé tentar negociar com 
a direita. Procurará governar, então, assumindo sua condição de líder popular e se apoiando nas forças progressistas e de esquerda. Nesse caso, considerando que dificilmente o novo congresso que sairá das urnas nas eleiçóes de 2018 terá um perfil menos conservador do que o atual, será necessário manter a frente popular mobilizada sob a liderança dos movimentos sociais e dos sindicatos das diferentes categorias de trabalhadores para revogar as medidas antinacionais e antipopulares e avançar;

- Lula é impedido de se candidatar. Nesse cenário, os arautos do golpe estariam em situação difícil, tendo sua legitimidade ainda mais contestada como, aliás, reconhece a própria Revista Veja, em sua edição de 13 de dezembro de 2017, por meio de um de seus principais articulistas, Roberto Pompeu de Toledo, que afirmou: "a eleição sem ele (Lula) não ajudará a superar o triplo trauma do atual período presidencial". E, mais adiante, confessa: "Quem quer ver Lula derrotado deve torcer para que o seja nas urnas. Lula impedido será um fantasma a assombrar não apenas a eleição, mas o mandato presidencial que se seguirá” (TOLEDO, 2017);

- Lula disputa as eleiçôes e é derrotado. Este é o cenário dos sonhos dos golpistas, independentemente de quem venha a ser eleito: Alckmin, Meirelles, Marina e até mesmo Bolsonaro. Com a vitória eleitoral contra Lula, eles se sentirão legitimados e livres para dar continuidade à sua política entreguista e antipopular.

Enfim, qualquer que seja o cenário que venha a prevalecer, é preciso organizar e manter mobilizada a resistência das forças progressistas e populares, cuja orientação básica me parece estar contida no programa mínimo da Frente Brasil Popular, que tem o condão de orientar tanto as manifestaçóes contra o golpe como os encaminhamentos referentes às eleiçóes de 2018. Infelizmente, esse programa, lançado como Plano Popular de Emergência em 29 de maio de 2017, no Tuca, em São Paulo, parece ter caído no esquecimento. Girando em torno de dez eixos (democratização do Estado; política de desenvolvimento, emprego e renda; reforma agrária e agricultura familiar; reforma tributária; direitos sociais e trabalhistas; direito à saúde, à educação, à cultura, à moradia; segurança pública; direitos humanos e cidadania; defesa do meio ambiente e política externa soberana), entendo que esse plano deve ser retomado como estratégia de enfrentamento ao movimento reacionário e autoritário que tomou conta do país com o golpe, que provocou um verdadeiro "suicídio democrático" na política brasileira. Concluo, então, com uma notícia alvissareira: a realizaçáo, nesse momento em que termino a redaçáo dessa resposta à entrevista, da $2^{\text {a }}$ Conferência Nacional da Frente Brasil Popular, nos dias 9 e 10 de dezembro, na Escola Nacional Florestan Fernandes, na qual foi anunciada a realização, no primeiro semestre de 2018, do Congresso do Povo Brasileiro, com o objetivo de "construir com o povo e para o povo um projeto de nação". 


\section{Referências}

BRASIL. Lei no 9.448, de 14 de março de 1997. Brasil, 1997a. Disponível em: shttp:// www.planalto.gov.br/ccivil 03/leis/19448.htm>. Acesso em: 12 jan. 2018.

. Lei no 13.005, de 15 de junho de 2014. Aprova o Plano Nacional de Educação PNE e dá outras providências. Brasil, 2014. Disponível em: $\leq$ http://www2.camara.leg. br/legin/fed/lei/2014/lei-13005-25-junho-2014-778970-publicacaooriginal-144468-pl. html . Acesso em: 12 jan. 2018.

Medida Provisória no 746, de 22 de setembro de 2016. Brasília, 22 set. 2016. Disponível em: <http://portal.mec.gov.br/index.php?option=com docman\&view=down load\&alias $=48601-\mathrm{mp}-746$-ensino-medio-link-pdf\&category slug=setembro-2016pdf\&Itemid=30192>. Acesso em: 12 jan. 2018.

. Medida Provisória no 1.568, de 14 de fevereiro de 1997. Brasil, 1997b. Disponível em: <http://www.planalto.gov.br/ccivil_03/MPV/Antigas/1568.htm>. Acesso em: 12 jan. 2018.

MARX, Karl. O Capital. Rio de Janeiro: Civilização Brasileira, 1968

. O dezoito Brumário de Luís Bonaparte. Sáo Paulo: Boitempo, 2011.

MARX, K.; ENGELS, F. Manifesto do Partido Comunista, 2a ed. São Paulo: Escriba, 1968.

RAVITCH, D. "Nota mais alta não é educação melhor". O Estado de São Paulo, 02 de agosto de 2010, p. 16.

SAVIANI, D. Escola e democracia, 42a ed. Campinas: Autores Associados, 2012.

. História das ideias pedagógicas no Brasil. 4. ed. Campinas: Autores Associados, 2013.

. Pedagogia histórico-crítica: primeiras aproximaçôes, $11^{\mathrm{a}}$ ed., $2^{\mathrm{a}}$ reimpressão. Campinas: Autores Associados, 2013.

- Sistema Nacional de Educação e Plano Nacional de Educação: significado, controvérsias e perspectivas. 2. ed. Campinas: Autores Associados, 2017b.

TOLEDO, R. P. “Lula e 2018”. Revista Veja, Edição no 2.560, de 13 de dezembro de 2017, última página.

VILLAMÉA, Luiza. "Como derrubar um governo". Revista Brasileiros, n.109, agosto de 2016, p. 26-38.

Recebido em 17 de janeiro de 2018.

Aprovado em 04 de julho de 2018.

(C) 2018 Centro de Estudos Educação e Sociedade - CEDES Este é um artigo de acesso aberto distribuído nos termos de licença Creative Commons. 